\title{
Trauma care inside and outside business hours: comparison of process quality and outcome indicators in a German level-1 trauma center
}

\author{
Wolfgang Parsch, Markus Loibl, Uli Schmucker, Franz Hilber, Michael Nerlich and Antonio Ernstberger
}

\begin{abstract}
Background: Optimal care of multiple trauma patients has to be at a high level around the clock. Trauma care algorithms and guidelines are available, yet it remains unclear if the time of admission to the trauma room affects the quality of care and outcomes. Hence the present study intends to compare the quality of trauma room care of multiple severely injured patients at a level-1 trauma center depending on the time of admission.

Methods: A total of 394 multiple trauma patients with an ISS $\geq 16$ were included into this study (observation period: 52 months). Patients were grouped by the time and date of their admission to the trauma room [business hours (BH): weekdays from 8:00 a.m. to 4:00 p.m. vs. non-business hours (NBH): outside BH]. The study analysed differences in patient demographics, trauma room treatment and outcome.

Results: The study sample was comparable in all basic characteristics [mean ISS: $32.3 \pm 14.3$ (BH) vs. $32.6 \pm 14.4$ (NBH), $p=0.853$; mean age: $40.8 \pm 21.0(\mathrm{BH})$ vs. $37.7 \pm 20.2$ years $(\mathrm{NBH}), \mathrm{p}=0.278]$. Similar values were found for the time needed for single interventions, like arterial access [4.8 $\pm 3.9 \mathrm{~min}(\mathrm{BH})$ vs. $4.9 \pm 3.4 \mathrm{~min}(\mathrm{NBH}), \mathrm{p}=0.496$ ] and quality-assessment parameters, like time until $\mathrm{CT}$ [28.5 $\pm 18.7 \mathrm{~min}(\mathrm{BH}), \mathrm{vs} .27 .3 \pm 9.5) \mathrm{min}(\mathrm{NBH}), \mathrm{p}=0.637]$. There was no difference for the $24 \mathrm{~h}$ mortality and overall hospital mortality in $\mathrm{BH}$ and $\mathrm{NBH}$, with $13.5 \%$ vs. 9.1\% ( $p=0.206)$ and, $21.9 \%$ vs. $15.4 \%(p=0.144)$, respectively. The Glasgow Outcome Scale (GOS) comparison revealed no difference $[3.7 \pm 1.6(\mathrm{BH})$ vs. $3.9 \pm 1.5(\mathrm{NBH}), \mathrm{p}=0.305]$. In general, the observed demographic, injury severity, care quality and outcome parameters revealed no significant difference between the two time periods $\mathrm{BH}$ and $\mathrm{NBH}$.

Conclusions: The study hospital provides multiple trauma patient care at comparable quality irrespective of time of admission to the trauma room. These results might be attributable to the standardization of the treatment process using established principles, algorithms and guidelines as well as to the resources available in a level-1 trauma center.
\end{abstract}

Keywords: Multiple trauma patient, Office/business hours, Out of hours, Process quality management, Severely injured patient

\section{Background}

Trauma is one of the most frequent causes of death and disability around the world [1]. According to the Global Burden of Disease study $10 \%$ of all deaths result from injury [2]. Therefore, many trauma education initiatives have been implemented aiming at reducing mortality. Especially when the multiple severely injured is concerned, trauma care quality has to be maintained efficiently on a constant high level around the clock [3].

\footnotetext{
*Correspondence: toni.ernstberger@ukr.de

Department of Trauma Surgery, University Hospital Regensburg,

Franz-Josef-Strauß-Allee 11, 93042 Regensburg, Germany
}

The "golden hour of shock" - that was postulated already in 1976 - emphasizes the significance of time and time loss [4]. Consequently a set of quality management related structures and processes were developed and in the past four decades:

\section{Trauma care algorithms and training}

Studies consistently report that a trauma room algorithm has a positive effect on patient care [5-7]. Concepts like Advanced Trauma Life Support (ATLS) or European Trauma Course (ETC) aim at ensuring efficient trauma room care workflows and preventing secondary injury [8]. 
The regular trauma room treatment of the study hospital is based on the ATLS-algorithm and is divided into three parts:

1. Resuscitation phase with first and second survey

2. Whole-body Computed Tomography (CT)

3. Finalization of diagnostics and determination of further treatment

Trauma registries for quality management and research Trauma registries have been established as a tool for quality assessment over the last decades. In Germany, the TraumaRegister DGU ${ }^{\circledR}$ (TR-DGU) of the German Trauma Society (DGU) has been invented more than 20 years ago in order to collect and process data on the prehospital and clinical course. Each of the $600+$ participating hospitals receive an annual report [3]. Comparable trauma registers are available, i.e. the Trauma Audit \& Research Network (TARN) in the UK [9].

\section{Establishment of designated trauma centers}

Usually hospitals are categorized as either Level-1, -2 or -3 trauma center. There is evidence from previous studies that a trauma system with designated trauma centers improves the survival rate and reduces the mortality rate by up to $15 \%$ [10-12].

The requirements for a level-1 trauma center are: [13]

1. 24/7 emergency department and trauma room service

2. 24/7 intensive care service including $24 / 7$ admission of referred patients

3. 24/7 emergency surgery service

4. Immediate $24 / 7$ availability of all specialists needed for interdisciplinary trauma care

Nevertheless, patient care including trauma care is usually forced into a system of business $(\mathrm{BH})$ and nonbusiness hours $(\mathrm{NBH})$.

It is common sense that the overall resources available for trauma care (i.e. manpower) are substantially higher during $\mathrm{BH}$ compared to $\mathrm{NBH}$, when many trauma team members are on duty.

The aim of this study was to evaluate the quality of multiple severely injured trauma care in $\mathrm{BH}$ and $\mathrm{NBH}$. Differences in patient demographics, quality indicators in trauma room treatment (e.g. time to $\mathrm{CT}$ ), and outcome parameters were assessed. To the authors' knowledge, this is the first study that evaluates the quality of trauma care at various hours, which includes a set of time periods to complete a certain intervention from a large study sample.

\section{Methods}

Study Sample

The inclusion criteria are listed below:
- Admission to trauma room during the study period (September 2007 - December 2011)

- Presence of a trained research follower for case documentation

- Injury Severity Score (ISS) $\geq 16$

A total of 757 patients were admitted to our trauma room during the study period, of which 499 presented with an ISS $\geq 16$. A research fellow was not present in 105 of these 499 cases in the trauma room the entire time for various reasons; therefore these data sets were not used in this study. The remaining 394 cases are henceforth referred to as "study sample".

The study sample was divided into the $\mathrm{BH}$ sample (weekdays [8:00 am; 4:00 pm]) and the NBH sample (weekdays] 4:00 pm; 8:00 am[or weekends or public holidays).

The catchment area of the study hospital (university hospital and level-1 trauma center) covers approximately $20.000 \mathrm{~km}^{2}$ with a population of two million residents. Ground based and helicopter air rescue services are available on a $24 / 7$ basis. The helicopter is used for air rescue and intensive care patient transport. During the night, air rescue can only be called by the emergency physician on scene [14].

\section{Trauma team and care algorithm}

The trauma room team comprises one trauma surgery consultant and one resident, one radiologist with one radiographer, one anesthesiologist with one nurse and two emergency nurses. Other disciplines (i.e. neurosurgery) can be consulted at any time. During NBH, these consultants are on call.

The intra-hospital workflow begins with the announcement of the trauma patient by the rescue coordination center. Such announcements trigger a set of pre-determined workflows, including the immediate call of consultants required for the case. Upon arrival of the patient, the history and clinical course are presented by the emergency physician. Thereafter, the primary survey begins. The aim of this primary survey is to rapidly resuscitate and examine the patient according to the ABCDE-concept [15]. The secondary survey starts after the stabilization of all vital functions and aims at identifying all anatomic injuries [16]. If stable, the patient is then transferred to the adjacent CT room and a whole-body CT is performed. Upon completion, the patient is transported back to the trauma room for a second trauma room phase.

\section{Data acquisition}

The whole trauma room phase was documented by a trained research fellow, who was also in charge of capturing the pre-hospital data from the respective patient records. 
Table 1 Basic characteristics: Patients assigned to groups depending on their time and date of arrival in the trauma room

\begin{tabular}{llllllll}
\hline & $\mathbf{n}$ (total) & mean (total) \pm SD (total) & $\mathbf{n}(\mathbf{B H})$ & mean $(\mathbf{B H}) \pm \mathbf{S D}(\mathbf{B H})$ & $\mathbf{n}(\mathbf{N B H})$ & mean (NBH) \pm SD (NBH) & $\mathbf{p}$-value \\
\hline Age (years) & 394 & $38.5 \pm 20.4$ & 96 & $40.8 \pm 21.0$ & 298 & $37.7 \pm 20.2$ & 0.278 \\
Male (\%) & $285(72.3 \%)$ & & $62(64.6 \%)$ & & $223(74.8 \%)$ & 0.510 \\
ISS & 394 & $32.5 \pm 14.3$ & 96 & $32.3 \pm 14.3$ & 298 & $32.6 \pm 14.4$ \\
NISS & 394 & $39.5 \pm 16.1$ & 96 & $40.2 \pm 16.5$ & 298 & $39.3 \pm 16.0$ & 0.853 \\
TRISS & 302 & $0.72 \pm 0.34$ & 75 & $0.71 \pm 0.36$ & 227 & $0.72 \pm 0.33$ & 0.675 \\
RISC & 388 & $24.1 \pm 30.9$ & 95 & $28.4 \pm 33.5$ & 293 & $22.7 \pm 29.9$ & 0.923 \\
ASA & 248 & $1.3 \pm 0.6$ & 54 & $1.3 \pm 0.6$ & 194 & $1.4 \pm 0.6$ & 0.327 \\
\hline
\end{tabular}

ASA: American Society of Anesthesiologists Classification, ISS: Injury Severity Score, NISS: New Injury Severity Score, RISC: Revised Injury Severity Classification Score, TRISS: Trauma and Injury Severity Score.

A total of 450 items were recorded in each patient, of which 130 were the standard data set of the trauma registry of the German Trauma Society (TraumaRegister $\left.\mathrm{DGU}^{\odot}\right)$. The fundamental part was the 130 items of the TR-DGU. The data inputted into the TR-DGU contained information about patient demographics and defined treatment time points: pre-hospital, trauma room, ICU and discharge. Furthermore, the TR-DGU documents the diagnosis and grade of injury according to the Abbreviated Injury Scale (AIS) [17], Injury Severity Score (ISS) [18], New Injury Severity Score (NISS) [19], Trauma and Injury Severity Score (TRISS) [20] and the Revised Injury Severity Classification Score (RISC-Score) [21]. Moreover, the ASA physical status classification system is recorded for each patient [22]. Furthermore, the time points for interventions and operations, and outcome according to the Glasgow Outcome Scale (GOS) [23]) were gathered [24].

The additional 320 items precisely recorded the time to and the duration of a broad spectrum of diagnostic and therapeutic interventions (e.g. chest tube, intubation, intravenous lines or splinting of the extremities) until admission to the ICU, transport to the operating room, or death.
In addition, all emergency physicians were asked to complete a standardized questionnaire on the perceived quality of the trauma room team on charge and available equipment.

\section{Statistics}

Statistical analysis was performed with IBM SPSS 21.0.0 for Windows. Normality was tested with the KolmogorovSmirnov test. The Chi-square test was used to analyze dichotomous variables, the unpaired $t$-test and MannWhitney $U$ test were used to analyze continuous variables. Data are presented as mean \pm standard deviation. p-values $<0.05$ were considered statistical significant in all tests. An outcome analysis was performed by calculating the Standardized Mortality Ratio (SMR) of the $\mathrm{BH}$ and $\mathrm{NBH}$ patients for their TRISS- and RISCprognosis.

\section{Ethical considerations}

The study was approved by the Institutional Review Board of the University of Regensburg (Number 14101-0004).

Table 2 Comparison of prehospital parameters of BH and NBH

\begin{tabular}{|c|c|c|c|c|c|c|c|}
\hline & n (Total) & mean (total) $\pm S D$ (total) & n (BH) & mean $(\mathrm{BH}) \pm \mathrm{SD}(\mathrm{BH})$ & $\mathrm{n}(\mathrm{NBH})$ & mean $(\mathrm{NBH}) \pm \mathrm{SD}(\mathrm{NBH})$ & $p$-value \\
\hline \multirow[t]{2}{*}{ Air-rescue (\%) } & 232 & & 65 & & 167 & & 0.025 \\
\hline & $(58.8 \%)$ & & $(67.7 \%)$ & & (56.0\%) & & \\
\hline \multirow[t]{2}{*}{ Prehospital intubation (\%) } & 286 & & 67 & & 219 & & 0.450 \\
\hline & $(72.6 \%)$ & & $(69.8 \%)$ & & (73.5\%) & & \\
\hline Initial GCS & 323 & $10.0 \pm 4.7$ & 80 & $10.0 \pm 4.7$ & 243 & $10.0 \pm 4.7$ & 0.964 \\
\hline Heart rate prehospital (1/min) & 315 & $94.1 \pm 30.6$ & 79 & $92.3 \pm 35.8$ & 236 & $94.7 \pm 28.7$ & 0.587 \\
\hline RR (sys) prehospital (mmHg) & 311 & $108.9 \pm 39.6$ & 77 & $105.6 \pm 42.9$ & 234 & $110.0 \pm 38.5$ & 0.419 \\
\hline \multirow[t]{2}{*}{$\mathrm{RR} \leq 90 \mathrm{mmHg}$ prehospital (\%) } & 98 & & 29 & & 69 & & 0.180 \\
\hline & $(31.5 \%)$ & & $(37.7 \%)$ & & $(29.5 \%)$ & & \\
\hline $\mathrm{SpO}_{2}$ prehospital (\%) & 290 & $90.4 \pm 15.6$ & 68 & $88.6 \pm 19.9$ & 222 & $91.0 \pm 14.0$ & 0.693 \\
\hline
\end{tabular}

The proportion of patients with prehospital $\mathrm{RR} \leq 90 \mathrm{mmHg}$ is calculated from the patients with available blood pressure values. RR: Blood pressure. 
Table 3 Comparison of parameters on arrival of $\mathrm{BH}$ and NBH

\begin{tabular}{|c|c|c|c|c|c|c|c|}
\hline & n (Total) & $\begin{array}{l}\text { mean (total) } \\
\pm \text { SD (total) }\end{array}$ & $\mathrm{n}(\mathrm{BH})$ & $\begin{array}{l}\text { mean }(\mathrm{BH}) \\
\pm \mathrm{SD}(\mathrm{BH})\end{array}$ & $\mathrm{n}(\mathrm{NBH})$ & $\begin{array}{l}\text { mean }(\mathrm{NBH}) \\
\pm \mathrm{SD}(\mathrm{NBH})\end{array}$ & $p$-value \\
\hline Time accident to admission (min) & 328 & $89.8 \pm 37.1$ & 81 & $83.6 \pm 26.3$ & 247 & $91.8 \pm 39.9$ & 0.367 \\
\hline Body temperature on arrival $\left({ }^{\circ} \mathrm{C}\right)$ & 333 & $35.9 \pm 1.3$ & 82 & $35.8 \pm 1.2$ & 251 & $35.9 \pm 1.3$ & 0.149 \\
\hline Heart rate on arrival ( $1 / \mathrm{min})$ & 388 & $89.9 \pm 23.0$ & 95 & $90.1 \pm 22.5$ & 293 & $89.9 \pm 23.2$ & 0.952 \\
\hline RR systolic on arrival $(\mathrm{mmHg})$ & 387 & $118.9 \pm 32.1$ & 95 & $116.5 \pm 32.2$ & 292 & $119.7 \pm 32.0$ & 0.391 \\
\hline $\mathrm{RR} \leq 90 \mathrm{mmHg}$ on arrival (\%) & $62(16.0 \%)$ & & $20(21.1 \%)$ & & $42(14.4 \%)$ & & 0.124 \\
\hline $\mathrm{SpO}_{2}$ on arrival (\%) & 380 & $96.7 \pm 9.0$ & 93 & $97.0 \pm 5.5$ & 287 & $96.6 \pm 9.9$ & 0.557 \\
\hline Transfusion $\geq 10$ ECs (\%) & $17(4.3 \%)$ & & $7(7.3 \%)$ & & $10(3.4 \%)$ & & 0.100 \\
\hline
\end{tabular}

The proportion of patients with $\mathrm{RR} \leq 90 \mathrm{mmHg}$ on arrival is calculated from the patients with available blood pressure values. RR: Blood pressure.

\section{Results}

\section{Demography}

The study sample consists of 394 patients. 96 (24\%) of these were admitted to the hospital during $\mathrm{BH}$ and 298 (76\%) patients were admitted during NBH. Significantly more males than females (72\% versus $28 \%$ ) were included. The mean age was $38.5+20.4$ years (Table 1 ).

\section{Injury severity}

The mean ISS was $32.5 \pm 14.3$ [BH: $32.3 \pm 14.3, \mathrm{NBH}$ : $32.6 \pm 14.4, \mathrm{p}=0.853]$ with no significant difference between $\mathrm{BH}$ and $\mathrm{NBH}$. Comparably, there was also no significant difference for the NISS, TRISS, RISC or ASA Classification, $\mathrm{p} \geq 0.251$ (Table 1).

Similarly, there was no difference between $\mathrm{BH}$ and $\mathrm{NBH}$ for the patients who received a whole-body CT or were treated with a mass-transfusion (> 10 erythrocyte concentrate (EC)) (Table 1).

Regarding the type of transport, helicopter transport was significantly more frequent in the $\mathrm{BH}$ sample compared to the NBH sample [BH: $n=65(68 \%$ of all $96 \mathrm{BH}$ patients), NBH: $n=167$ (56\% of all $298 \mathrm{NBH}$ patients), $\mathrm{p}=0.025]$. Table 2 demonstrates that other prehospital parameters do not show any statistical difference.

The parameters recorded at the admission of the patients didn't differ in any aspect. Overall, 62 patients (16.0\%) were in shock (systolic blood pressure $\leq 90 \mathrm{mmHg}$ ) on hospital admission [BH: $\mathrm{n}=20$ (21.1\%), NBH: $\mathrm{n}=42$ (14.4\%), $\mathrm{p}=0.124]$ (Table 3).

\section{Analysis of clinical care}

The mean length of stay in the trauma room was $62.7 \pm$ 28.4 minutes with no significant difference between the $\mathrm{BH}$ sample and the $\mathrm{NBH}$ sample $(63.9 \pm 29.7$ versus $62.3 \pm$ 28.0 minutes, $\mathrm{p}=0.700$ ). Likewise, the time from arrival at the trauma room to the beginning of the CT scan was similar during $\mathrm{BH}$ and $\mathrm{NBH}$ with $28.5 \pm 18.7$ and $27.3 \pm 9.5-$ minutes, respectively, $\mathrm{p}=0.637$. The proportion of patients, who received a whole-body CT scan was similar with $89.6 \%$ (86 patients) and $89.9 \%$ (268 patients) in $\mathrm{BH}$ and $\mathrm{NBH}$, respectively, $\mathrm{p}=0.921$ (Table 4 ).

In addition no significant difference was observed regarding the time needed to institute arterial lines, intravenous lines, central venous catheter, urinary catheter, and limb splinting (see Table 4 and Figure 1).

Table 4 Trauma room management and treatment comparison

\begin{tabular}{|c|c|c|c|c|c|c|c|}
\hline & n (total) & $\begin{array}{l}\text { mean (total) } \\
\pm S D \text { (total) }\end{array}$ & n $(\mathrm{BH})$ & $\begin{array}{l}\text { mean }(\mathrm{BH}) \\
\pm \mathrm{SD}(\mathrm{BH})\end{array}$ & $\mathrm{n}(\mathrm{NBH})$ & $\begin{array}{l}\text { mean (NBH) } \\
\pm \mathrm{SD}(\mathrm{NBH})\end{array}$ & p-value \\
\hline Time until FAST-Sono (min) & 314 & $6.0 \pm 4.5$ & 78 & $5.7 \pm 3.0$ & 236 & $6.1 \pm 4.9$ & 0.763 \\
\hline Time until CT (min) & 351 & $27.6 \pm 12.4$ & 86 & $28.5 \pm 18.7$ & 265 & $27.3 \pm 9.5$ & 0.637 \\
\hline Time until discharge from TR (min) & 375 & $62.7 \pm 28.4$ & 93 & $63.9 \pm 29.7$ & 282 & $62.3 \pm 28.0$ & 0.700 \\
\hline Time for intubation (min) & $22(5.6 \%)$ & $4.0 \pm 4.0$ & $4(4.2 \%)$ & $2.8 \pm 2.2$ & $18(6.0 \%)$ & $4.2 \pm 4.4$ & $0.460(0.487)$ \\
\hline Time for artery access (min) & $220(55.8 \%)$ & $4.9 \pm 3.6$ & $59(61.5 \%)$ & $4.8 \pm 3.9$ & $161(54.0 \%)$ & $4.9 \pm 3.4$ & $0.496(0.202)$ \\
\hline Time for CVL (min) & $54(13.7 \%)$ & $7.2 \pm 5.5$ & $15(15.6 \%)$ & $6.0 \pm 5.6$ & $39(13.1 \%)$ & $7.7 \pm 5.5$ & $0.084(0.529)$ \\
\hline Time for peripherial access (min) & $66(16.8 \%)$ & $1.8 \pm 1.3$ & $12(12.5 \%)$ & $1.8 \pm 0.9$ & $54(18.1 \%)$ & $1.8 \pm 1.4$ & $0.757(0.200)$ \\
\hline Time for thorax-drainage (min) & $19(4.8 \%)$ & $7.4 \pm 4.3$ & $5(5.2 \%)$ & $10.4 \pm 6.5$ & $14(4.7 \%)$ & $6.3 \pm 2.7$ & $0.243(0.542)$ \\
\hline Time for splinting (min) & $89(22.6 \%)$ & $4.1 \pm 3.4$ & $23(24.0 \%)$ & $4.2 \pm 3.9$ & $66(22.1 \%)$ & $4.1 \pm 3.3$ & $0.658(0.712)$ \\
\hline Time for permanent catheter (min) & $229(58.1 \%)$ & $2.1 \pm 1.4$ & $51(53.1 \%)$ & $2.2 \pm 1.9$ & $178(59.7 \%)$ & $2.0 \pm 1.2$ & $0.846(0.254)$ \\
\hline
\end{tabular}

TR: Trauma room, CVL: Central Venous Line. 


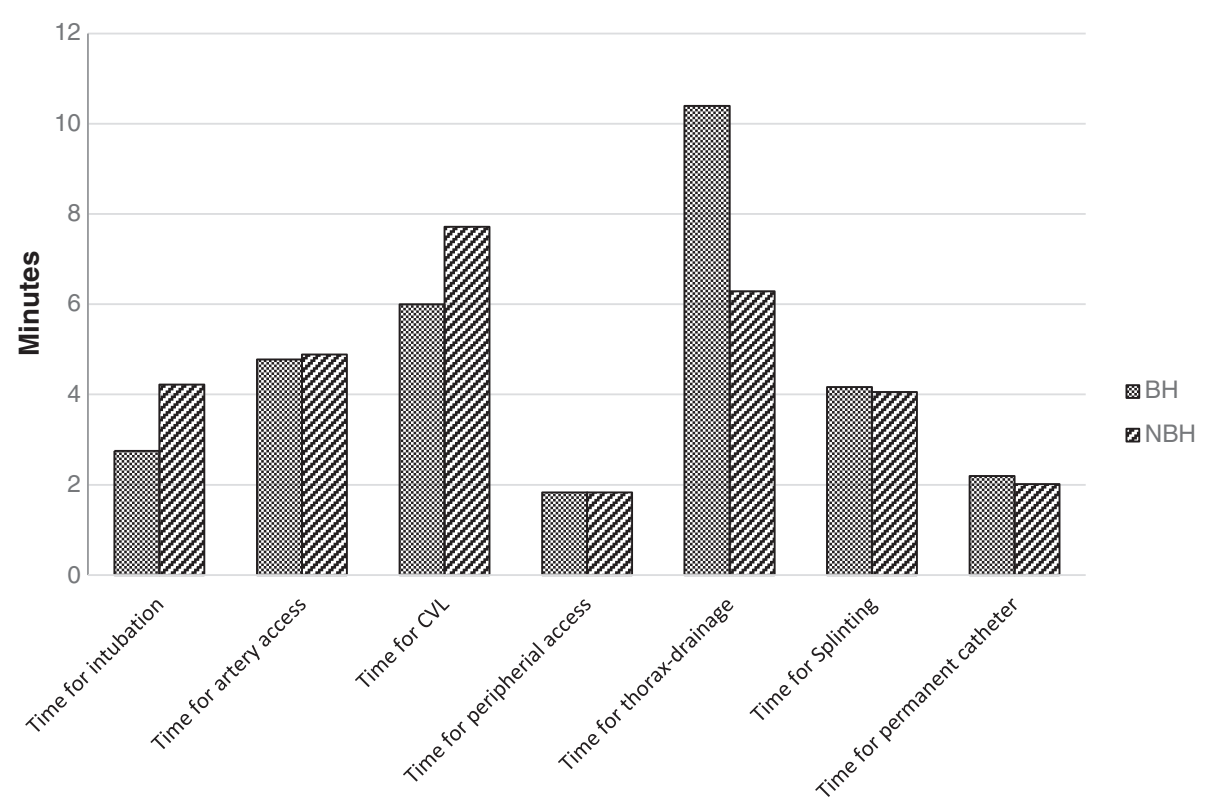

Figure 1 Comparison of length in time for single interventions. CVL: Central Venous Line.

\section{Outcome analysis}

The early mortality rate [death within 24 hours: $\mathrm{BH}: \mathrm{n}=13$ (13.5\%), NBH: $n=27$ (9.1\%), $p=0.206$ ], as well as the inhospital mortality rate [BH: $n=21(21.9 \%), N B H: n=46$ (15.4\%), $\mathrm{p}=0.144$ ] showed trends towards higher mortality rates in the BH-sample. However, these were not statistical significant. The difference between the calculated RISCprognosis and the observed mortality was $6.4 \%$ and $7.2 \%$ in the $\mathrm{BH}$ and $\mathrm{NBH}$ samples, respectively (Figure 2). The TRISS-SMR-Rate was 0.76 (95\% CI 0.48-1.05) during BH and 0.56 (95\% CI 0.41-0.71) during NBH (see Table 5). On average, patients were intubated for $7.2 \pm 10.2$ and 7.4 \pm 10.0 days $(\mathrm{p}=0.856)$ when admitted in $\mathrm{BH}$ and $\mathrm{NBH}$, respectively. The mean length of ICU stay was $11.5 \pm 14.9$ and $12.0 \pm 11.9$ days $(\mathrm{p}=0.183)$, and the mean length of hospital stay was $21.8 \pm 21.0$ and $22.2 \pm 16.6$ days in $\mathrm{BH}$ and NBH $(\mathrm{p}=0.268)$. The mean GOS in both groups was comparable with $3.7 \pm 1.6$ and $3.9 \pm 1.5$ in $\mathrm{BH}$ and $\mathrm{NBH}$ $(\mathrm{p}=0.305)$. The prevalence of MOF (Multi Organ Failure) and sepsis was similar in both groups (Table 6).

A sensitivity analysis with different start time (7:00; 7:30; 8:30; 9:00 a.m.) or end time (3:00; 3:30; 4:30; 5:00 p.m.) revealed no major differences in injury severity, treatment or outcome to the chosen interval.

\section{Discussion}

The present study compares the quality of multiple trauma patient care and outcome between $\mathrm{BH}$ and NBH. We demonstrated that the time of admission had no measurable impact on a broad spectrum of monitored

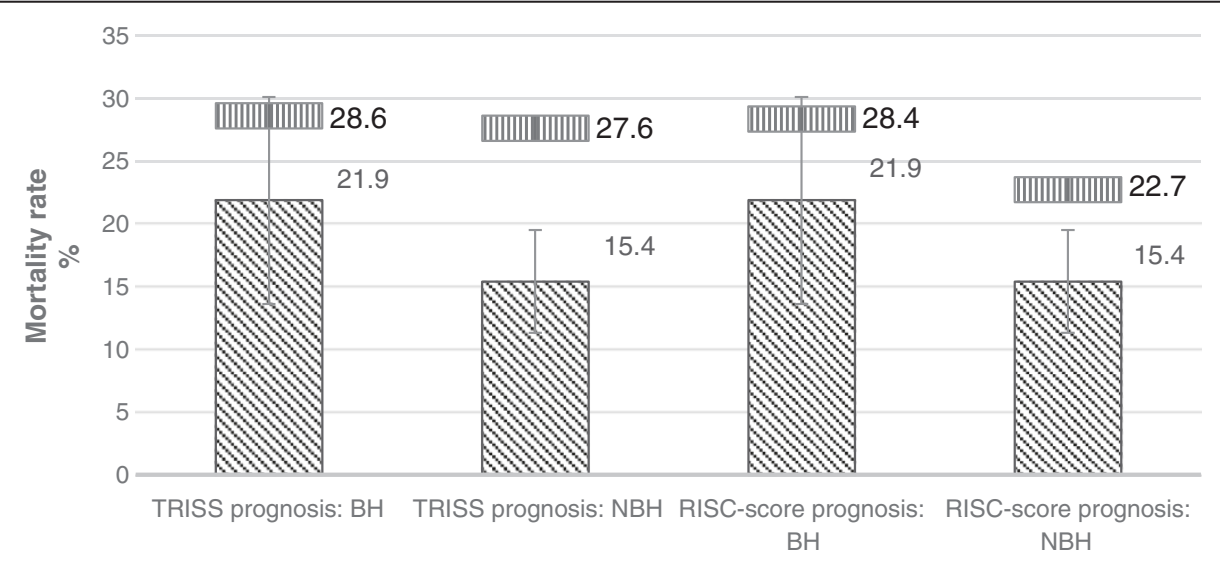

Figure 2 Observed vs. expected in hospital mortality: A TRISS and RISC-comparison. The upper bar shows the expected mortality, the lower bar the observed mortality. 
Table 5 Comparison of SMR: TRISS and RISC

\begin{tabular}{lll}
\hline & SMR & Cl 95\% \\
\hline BH: TRISS & 0.764 & $0.476-1.053$ \\
NBH: TRISS & 0.559 & $0.410-0.707$ \\
BH: RISC & 0.771 & $0.480-1.063$ \\
NBH: RISC & 0.679 & $0.499-0.860$ \\
\hline
\end{tabular}

Cl: Confidence interval, SMR: Standardized Mortality Ratio, RISC: Revised Injury Severity Classification Score, TRISS: Trauma and Injury Severity Score.

variables that served as process and quality indicators for trauma care and outcome at the study hospital which is a level-1 trauma center. We therefore conclude that a level-1 trauma center can provide high quality trauma care irrespective of the time of patient admission.

The observed patient sample is comparable to other multiple trauma patient-studies with regard to demographics and grade of injury (ISS: $29.7 \pm 13.0 / 28.8 \pm 12.1$ /median ISS 20 (IQR, 16-26)) [25-27].

Looking at the prehospital parameters, we found no differences between $\mathrm{BH}$ and $\mathrm{NBH}$, with the exception of the proportion of air lifted patients, which was significantly lower during $\mathrm{NBH}$. This might be partially attributable to the air rescue-algorithms in the study hospitals catchment area: after sunset, a helicopter can be demanded in addition by a ground emergency physician [28]. It has been shown previously that ordering an air rescue could result in a prolonged prehospital time although this had no impact on the outcome [29]. Interestingly, the rate of prehospital intubations is not affected by the time of admission which underlines the quality of the well-established area-wide 24 h-ground-emergency-service.

Likewise, we found no differences between $\mathrm{BH}$ and NBH with regard to the trauma room treatment parameters. It is well accepted that the human work performance decreases at night [30,31], however, an impact of $\mathrm{BH}$ and $\mathrm{NBH}$ on the monitored care and outcome parameters cannot be demonstrated. Data of the duration of single interventions are scarce. To the best knowledge of the authors, similar studies examining the duration of single interventions around the clock are not available. The lack of external benchmarks limits the comparability of this study. Nevertheless, the different time measurements (time-to-intervention or time period to complete a certain intervention) were comparable in the $\mathrm{BH}$ and NBH study sample. This indicates, that the trauma team instituted comparable trauma care around the clock.

Importantly, the core outcome " $24 \mathrm{~h}$ mortality" was similar in $\mathrm{BH}$ and $\mathrm{NBH}$. With respect to comparable patient demographics and injury severity, it could be presumed that the care during NBH was on the same level as during $\mathrm{BH}$. This might be attributable to a broad spectrum of factors, including standardized care algorithms, trauma care training and resources available in the level-1 study hospital. The observed mortality was up to $16 \%$ lower than in previous studies though sample characteristics were comparable. This finding is supported by the SMR-calculations of Huber-Wagner et. al. (0.68 - 0.77 vs. $0.85-0.98)$ $[25,32]$. The clinical outcome of trauma patients in $\mathrm{BH}$ versus NBH has been evaluated in very few studies so far [27,32-36]. In general, consistent results were obtained in regard to clinical outcome in $\mathrm{BH}$ and $\mathrm{NBH}$, however, the time needed to institute specific interventions was not recorded. In contrast, Di Bartolomeo et al. could demonstrate an off hour effect on trauma patients. This effect was most evident in transferred cases [37]. In other medical emergencies, like stroke [38-41] or myocardial infarction $[42,43]$ previous studies didn't come to a consistent conclusion regarding the impact of the hospital admission time on the outcome. Conflicting results can be found in the literature concerning time of admittance and outcome [44-48].

We emphasize that it is important to guarantee a constant high level of quality of care for major trauma patients. This includes that structural and trauma team requirements have to be fulfilled. Within our study

Table 6 Outcome comparison of BH and NBH

\begin{tabular}{|c|c|c|c|c|c|c|c|}
\hline & $\mathrm{n}$ (total) & $\begin{array}{l}\text { mean (total) } \\
\pm S D \text { (total) }\end{array}$ & $\mathrm{n}(\mathrm{BH})$ & $\begin{array}{l}\text { mean (BH) } \\
\pm \mathrm{SD}(\mathrm{BH}) \\
\end{array}$ & $\mathrm{n}(\mathrm{NBH})$ & $\begin{array}{l}\text { mean (NBH) } \\
\pm \text { SD (NBH) }\end{array}$ & $\mathrm{p}$-value \\
\hline GOS & 392 & $3.8 \pm 1.5$ & 95 & $3.7 \pm 1.6$ & 297 & $3.9 \pm 1.5$ & 0.305 \\
\hline $\mathrm{GOS}>=4$ & $265(67.6 \%)$ & & $59(62.1 \%)$ & & $206(69.4 \%)$ & & 0.188 \\
\hline Died within 24 h (\%) & $40(10.2 \%)$ & & $13(13.5 \%)$ & & $27(9.1 \%)$ & & 0.206 \\
\hline In hospital mortality (\%) & $67(17.0 \%)$ & & $21(21.9 \%)$ & & $46(15.4 \%)$ & & 0.144 \\
\hline Days intubated & 394 & $7.4 \pm 10.0$ & 96 & $7.2 \pm 10.2$ & 298 & $7.4 \pm 10.0$ & 0.856 \\
\hline Days on ICU & 372 & $11.9 \pm 12.7$ & 93 & $11.5 \pm 14.9$ & 279 & $12.0 \pm 11.9$ & 0.183 \\
\hline Days in hospital overall & 394 & $22.1 \pm 17.8$ & 96 & $21.8 \pm 21.0$ & 298 & $22.2 \pm 16.6$ & 0.268 \\
\hline Sepsis (\%) & $38(9.6 \%)$ & & $10(10.4 \%)$ & & $28(9.4 \%)$ & & 0.835 \\
\hline MOF (\%) & $163(41.4 \%)$ & & $38(39.6 \%)$ & & $125(41.9 \%)$ & & 0.559 \\
\hline
\end{tabular}

GOS: Glasgow Outcome Scale, MOF: Multi Organ Failure. 
setting (level-1 trauma center), it seems that there was sufficiently qualified personnel available during business hours as well as during non-business hours [49].

Since this is a single center study, the chosen interval for $\mathrm{BH}$ from 8:00 a.m. to 4:00 p.m. represents the shift time of all participating disciplines in particular of the trauma surgery and anaesthesia in the study hospital. In other hospitals, different intervals might fit better.

Despite a large and well-defined patient sample, the present study has a number of limitations. First of all, it is a cohort study with a retrospective design. Second, information on prehospital deaths is not provided since these were not recorded in the database. Third, due to missing data in the trauma registry of the German Trauma Society (TraumaRegister DGU ${ }^{\circ}$ ), TRISS was calculated in $76.6 \%$ of all 394 cases only whereas the RISC-score was completed in $98.5 \%$.

Fourth: For various reasons, the research fellow was not permanently present in 105 of 499 cases in the trauma room; therefore these data sets could not be used in this study as is might has biased the results.

Finally, even though the trauma room treatment was standardized, the treating trauma team differed; however, this limitation represents the daily routine in a clinic.

\section{Conclusions}

Based on 394 patients, this is the first study that shows that there were no major differences in characteristics, treatment or outcome between multiple trauma patients admitted during $\mathrm{BH}$ and those who were admitted during $\mathrm{NBH}$. This indicates comparable treatment in the sense of quality management regardless of admittance during $\mathrm{BH}$ or NBH. A well-trained staff, well-structured organization and other standardizations of the treatment process could be conducive to this result.

\section{Abbreviations}

AIS: Abbreviated Injury Scale; ASA: American Society of Anesthesiologists Classification; ATLS: Advanced Trauma Life Support; BH: Business Hours; CT: Computer Tomography; CVL: Central Venous Line; DGU: German Trauma Society; TR-DGU: TraumaRegister DGU®; EC: Erythrocyte Concentrate; ETC: European Trauma Course; GOS: Glasgow Outcome Scale; ICU: Intensive Care Unit; ISS: Injury Severity Score; MOF: Multi Organ Failure; NBH: NonBusiness Hours; NISS: New Injury Severity Score; RISC: Revised Injury Severity Classification Score; SD: Standard Deviation; SMR: Standardized Mortality Ratio; TARN: Trauma Audit \& Research Network; TR: Trauma room; TRISS: Trauma and Injury Severity Score.
}

\section{Competing interests}

The authors declare that they have no competing interests.

\section{Authors' contributions}

Participated in the idea, planning, data analysis and interpretation, statistical analysis, and writing the manuscript: WP, AE. Participated in data interpretation, and writing the manuscript: ML, US. Participated in data acquisition: FH, MN. Have read and approved the final version: WP, ML, US, $\mathrm{FH}, \mathrm{MN}, \mathrm{AE}$. All authors read and approved the final manuscript.

\section{Acknowledgements}

The publication of this work was supported by the German Research Foundation (DFG) within the funding programme Open Access Publishing. We thank Kelsey Markl for language editing.

Received: 3 July 2014 Accepted: 19 October 2014

Published online: 31 October 2014

\section{References}

1. Krug EG, Sharma GK, Lozano R: The global burden of injuries. Am J Public Health 2000, 90:523-526.

2. Murray CJ, Lopez AD: Mortality by cause for eight regions of the world: global burden of disease study. Lancet 1997, 349:1269-1276.

3. Ruchholtz S: External quality management in the clinical treatment of severely injured patients. Unfallchirurg 2004, 107:835-843.

4. Cowley RA: The resuscitation and stabilisation of major multiple trauma patients in a trauma center environment. Clin Med 1976, 83:14-22.

5. Ruchholtz S, Zintl B, Nast-Kolb D, Waydhas C, Schwender D, Pfeifer KJ, Schweiberer L: Quality management in the early treatment of patients with multiple injuries: II. Quality improvement guidelines. Unfallchirurg 1997, 100:859-866.

6. Bernhard M, Becker TK, Nowe T, Mohorovicic M, Sikinger M, Brenner T, Richter GM, Radeleff B, Meeder PJ, Büchler MW, Böttiger BW, Martin E, Gries $\mathrm{A}$ : Introduction of a treatment algorithm can improve the early management of emergency patients in the resuscitation room. Resuscitation 2007, 73:362-373.

7. Bishop M, Shoemaker WC, Avakian S, James E, Jackson G, Williams D, Meade $P$, Fleming A: Evaluation of a comprehensive algorithm for blunt and penetrating thoracic and abdominal trauma. Am Surg 1991, 57:737-746.

8. Collicott PE: Advanced trauma life support (atls): past, present, future-16Th stone lecture, American trauma society. J Trauma Inj Infect Crit Care 1992, 33:749-753.

9. Racy M, Al-Nammari S, Hing CB: A survey of trauma database utilisation in England. Injury 2013, 45:624-628.

10. Celso B, Tepas J, Langland-Orban B, Pracht E, Papa L, Lottenberg L, Flint L: A systematic review and meta-analysis comparing outcome of severely injured patients treated in trauma centers following the establishment of trauma systems. J Trauma 2006, 60:371-378. discussion 378.

11. MacKenzie EJ, Rivara FP, Jurkovich GJ, Nathens AB, Frey KP, Egleston BL, Salkever DS, Scharfstein DO: A national evaluation of the effect of trauma-center care on mortality. N Engl J Med 2006, 354:366-378.

12. Nirula R, Brasel K: Do trauma centers improve functional outcomes: a national trauma databank analysis? J Trauma 2006, 61:268-271.

13. American College of Surgeons: Reference Guide of Suggested Classification. Level 1 Trauma Center. [http://www.facs.org/trauma/vrc1.pdf]

14. Bayerisches Staatsministerum des Innern: [Bavarian air rescue service] [http://www.stmi.bayern.de/sicherheit/rettungswesen/luftrettung]

15. Stahel PF, Smith WR, Moore EE: Current trends in resuscitation strategy for the multiply injured patient. Injury 2009, 40:S27.

16. Shafizadeh $S$, Tjardes $T$, Steinhausen $E$, Balke M, Paffrath $T$, Bouillon B, Bäthis $\mathrm{H}$ : Advanced trauma life support $\left(A T L S^{\odot}\right)$ in the emergency room: is it suitable as an SOP? Orthopade 2010, 39:771-776.

17. Gennarelli TA, Wodzin E: AIS 2005: a contemporary injury scale. Injury 2006, 37:1083-1091.

18. Baker SP, O'Neill B, Haddon W, Long WB: The injury severity score: a method for describing patients with multiple injuries and evaluating emergency care. J Trauma 1974, 14:187-196.

19. Turner O, Baker SP, Long WB: A modification of the injury severity score that both improves accuracy and simplifies scoring. J Trauma 1997, 43:922-925. 925-926.

20. Boyd CR, Tolson MA, Copes WS: Evaluating trauma care: the TRISS method: trauma score and the injury severity score. J Trauma 1987, 27:370-378.

21. Lefering R: Development and validation of the revised injury severity classification score for severely injured patients. Eur J Trauma Emerg Surg 2009, 35:437-447.

22. American Society of Anesthesiologists: New classification of physical status. Anesthesiology 1963, 24:111.

23. Jennett $B$, Bond $M$ : Assessment of outcome after severe brain damage. Lancet 1975, 305:480-484. 
24. Helm M, Bitzl A, Klinger S, Lefering R, Lampl L, Kulla M: The TraumaRegister $\mathrm{DGU}^{\circledR}$ as the basis of medical quality management. Ten years experience of a national trauma centre exemplified by emerge the TraumaRegister $\mathrm{DGU}^{\circledast}$ as the basis of medical quality management. Unfallchirurg 2012 116:624-632.

25. Huber-Wagner S, Lefering R, Qvick L, Körner M, Kay MV, Pfeifer K, Reiser M, Mutschler W, Kanz K: Effect of whole-body CT during trauma resuscitation on survival: a retrospective, multicentre study. Lancet 2009, 373:1455-1461.

26. Huber-Wagner $S$, Biberthaler $P$, Häberle $S$, Wierer $M$, Dobritz $M$, Rummeny $E$, van Griensven M, Kanz K, Lefering R, Landoni G: Whole-body CT in haemodynamically unstable severely injured patients - a retrospective: multicentre study. PLOS One 2013, 8:68880.

27. Laupland KB, Ball CG, Kirkpatrick AW: Hospital mortality among major trauma victims admitted on weekends and evenings: a cohort study. J Trauma Manag Outcomes 2009, 3:8.

28. Institut für Notfallmedizin und Medizinmanagement (INM) Klinikum der Universität München: [Analysis of Needs of air Rescue in Bavaria] Bedarfsanalyse zur Luftrettung in Bayern. München: Institut für Notfallmedizin und Medizinmanagement (INM) Klinikum der Universität München; 2009.

29. Kleber C, Lefering R, Kleber AJ, Buschmann CT, Bail HJ, Schaser KD, Haas NP: Rescue time and survival of severely injured patients in Germany. Unfallchirurg 2012, 116:345-350.

30. Machi MS, Staum M, Callaway CW, Moore C, Jeong K, Suyama J, Patterson PD, Hostler D: The relationship between shift work, sleep, and cognition in career emergency physicians. Acad Emerg Med 2012, 19:85-91.

31. Smith-Coggins R, Rosekind MR, Hurd S, Buccino KR: Relationship of day versus night sleep to physician performance and mood. Ann Emerg Med 1994, 24:928-934.

32. Guly HR, Leighton G, Woodford M, Bouamra O, Lecky F: The effect of working hours on outcome from major trauma. Emerg Med J 2006, 23:276-280.

33. Dybdal B, Svane C, Hesselfeldt R, Steinmetz J, Sorensen AM, Rasmussen LS: Is there a diurnal difference in mortality of severely injured trauma patients? Emerg Med J 2013. Publishe online

34. Carr BG, Jenkins P, Branas CC, Wiebe DJ, Kim P, Schwab CW, Reilly PM: Does the trauma system protect against the weekend effect? J Trauma 2010, 69:1042-1047. discussion 1047-8.

35. Egol KA, Tolisano AM, Spratt KF, Koval KJ: Mortality rates following trauma: the difference is night and day. J Emerg Trauma Shock 2011, 4:178-183.

36. Søreide K: Temporal patterns of death after trauma: evaluation of circadian, diurnal, periodical and seasonal trends in 260 fatal injuries. Scand J Surg 2010, 99:235-239.

37. Di Bartolomeo S, Marino M, Ventura C, Trombetti S, de Palma R: A population based study on the night-time effect in trauma care. Emerg Med J 2014, 31:808-812.

38. Jauss $M$, Oertel $W$, Allendoerfer J, Misselwitz $B$, Hamer $\mathrm{H}$ : Bias in request for medical care and impact on outcome during office and non-office hours in stroke patients. Eur J Neurol 2009, 16:1165-1167.

39. Fang K, Churilov L, Weir L, Dong Q, Davis S, Yan B: Thrombolysis for acute ischemic stroke: Do patients treated Out of hours have a worse outcome? J Stroke Cerebrovasc Dis 2013, 23:427-432.

40. Streifler JY, Benderly M, Molshatzki N, Bornstein N, Tanne D: Off-hours admission for acute stroke is not associated with worse outcome-a nationwide Israeli stroke project. Eur J Neurol 2012, 19:643-647.

41. McKinney JS, Deng Y, Kasner SE, Kostis JB: Comprehensive stroke centers overcome the weekend versus weekday gap in stroke treatment and mortality. Stroke 2011, 42:2403-2409.

42. Kostis WJ, Demissie K, Marcella SW, Shao Y, Wilson AC, Moreyra AE: Weekend versus weekday admission and mortality from myocardial infarction. N Engl J Med 2007, 356:1099-1109.

43. Turin TC, Kita Y, Rumana N, Sugihara H, Morita Y, Tomioka N, Okayama A Nakamura $Y$, Ueshima $\mathrm{H}$ : Incidence, admission and case-fatality of acute myocardial infarction: weekend versus weekday in a Japanese population: 16-year results from Takashima AMI Registry (1988-2003). Eur J Epidemiol 2009, 24:93-100.

44. Kuijsten H, Brinkman S, Meynaar I, Spronk P, van der Spoel Jl, Bosman R, de Keizer NF, Abu-Hanna A, de Lange DW: Hospital mortality is associated with ICU admission time. Intensive Care Med 2010, 36:1765-1771.
45. Cavallazzi R, Marik PE, Hirani A, Pachinburavan M, Vasu TS, Leiby BE: Association between time of admission to the ICU and mortality: a systematic review and metaanalysis. Chest 2010, 138:68-75.

46. Bell CM, Redelmeier DA: Mortality among patients admitted to hospitals on weekends as compared with weekdays. N Engl J Med 2001, 345:663-668.

47. Sheu C, Tsai J, Hung J, Yang C, Hung H, Chong I, Huang M, Hwang J: Admission time and outcomes of patients in a medical intensive care unit. Kaohsiung J Med Sci 2007, 23:395-404.

48. Peeters B, Peeters B, Jansen NJ, Bollen CW, van Vught AJ, van der Heide D, Albers MJ: Off-hours admission and mortality in two pediatric intensive care units without 24-h in-house senior staff attendance. Intensive Care Med 2010, 36:1923-1927.

49. German Trauma Society: Whitebook on the Medical Care of the Severely Injured. 2nd edition. Berlin: Thieme; 2012.

doi:10.1186/s13049-014-0062-2

Cite this article as: Parsch et al:: Trauma care inside and outside business hours: comparison of process quality and outcome indicators in a German level-1 trauma center. Scandinavian Journal of Trauma, Resuscitation and Emergency Medicine 2014 22:62.

\section{Submit your next manuscript to BioMed Central and take full advantage of:}

- Convenient online submission

- Thorough peer review

- No space constraints or color figure charges

- Immediate publication on acceptance

- Inclusion in PubMed, CAS, Scopus and Google Scholar

- Research which is freely available for redistribution 